\title{
Clinico-demographic profile of young people presenting with refractive errors to a medical college hospital of Bihar, India
}

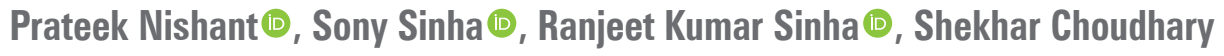 \\ Patna Medical College, Ashok Rajpath, Patna, Bihar, India
}

\begin{abstract}
BACKGROUND: Refractive errors are the second most important cause of blindness and account for $18 \%$ of the burden. An estimated 123.7 million people suffer from visual impairment due to unaddressed refractive errors worldwide. International agencies recognize that globally, there is insufficient data on the prevalence and types of refractive errors in different populations and age groups. The present study evaluated the proportion of refractive errors with their clinico-demographic context among 10-24-year old patients, presenting to the Ophthalmology Outpatient Department (OPD) of a tertiary hospital of Bihar state of India.

MATERIAL AND METHODS: This prospective, descriptive study collected information about refractive errors in 2739 eyes of 1482 young people. The association between the refractive errors and clinico-demographic variables such as age group, gender, residential background and educational status was evaluated using the chi-square test (taking $\mathrm{p}$ $<0.05$ as significant).

RESULTS: Hypermetropic errors were more common (51\%) comprising of hypermetropia (32\%) and hypermetropic astigmatism (19\%). They marginally exceeded myopic errors (about 49\%), comprising myopic astigmatism (26\%) and myopia (22\%) while mixed astigmatism was the least common (0.4\%). Myopic errors were significantly more common in the 10-14 years age group (76\%) while hypermetropic errors predominated in older age-groups (54\%, $\mathrm{p}<0.001)$. Myopia predominated in females $(39 \%)$ and in rural young people $(53 \%)$, myopic astigmatism in the illiterate $(45 \%)$ but hypermetropia in males $(37 \%, \mathrm{p}<0.001)$, urban $(35 \%, \mathrm{p}<0.001)$ and literate young people $(31 \%, \mathrm{p}<0.001)$.

CONCLUSIONS: This study revealed a broad picture of proportion and predominance of different refractive errors and their associations with clinico-demographic profile of the patients.
\end{abstract}

KEY WORDS: age distribution; sex distribution; residence characteristics; educational status; ametropia

Ophthalmol J 2020; Vol. 5, 93-100

\section{INTRODUCTION}

This study intended to explore the distribution of refractive errors with respect to clinico-demographic variables in young people (aged 10-24 years [1]) presenting to the Ophthalmology Outpatient
Department (OPD) of a medical college hospital, a premier tertiary care hospital of Bihar.

Refractive errors are the second most important cause of blindness and account for $18 \%$ of the burden. Of the estimated 2.2 billion people 
worldwide who have visual impairment or blindness, an estimated 123.7 million people suffer from visual impairment due to unaddressed refractive errors. They are the main cause of visual impairment in children aged $5-15$ years $[2,3]$. It has been estimated that over 40 million school-aged children have visual acuity of $\leq 6 / 12$ from uncorrected or improperly corrected refractive errors and that the highest prevalence is in South-East Asia and China, particularly in urban areas [4]. The $\mathrm{Na}$ tional Blindness and Visual Impairment Survey of India (2015-2019) revealed that refractive errors contribute to 29.6 per cent of visual impairment in 0-49 years age population [5].

The World Health Organization (WHO) and International Agency for the Prevention of Blindness (IAPB), recognize that globally, there is insufficient data on the prevalence and types of refractive errors in different populations and age groups [3]. The challenges in establishing an effective system to address the burden of uncorrected refractive errors in India include the development of optimally trained optometry workforce, the establishment of multi-tiered points of delivery of refractive care services and optical dispensing units, and seamless integration of these initiatives into existing or novel models of comprehensive eye care [6].

Given the aforesaid challenges, a large number of young people present to tertiary OPDs for refraction and prescription of glasses, the pattern and reasons for which have been enumerated in earlier publications $[8,9]$. The overall incidence of refractive errors has been reported to be up to $55 \%$ in ophthalmology OPDs of vision centres as well as tertiary hospitals [9-11]. Various hospital-based studies have concluded that myopic errors (myopia [11-18] or myopic astigmatism [19]) are the most common refractive errors; myopia is, in general, more prevalent than astigmatism and hypermetropia, and myopic astigmatism is more common compared to hypermetropic or mixed astigmatism.

The mean age of presentation of refractive errors in adolescents has been estimated to be 14.3 years, but the prevalence has been reported to be maximum in the extremes of adolescence $[9,10,18]$.

There is conflicting information on whether particular refractive errors are more prevalent in a particular gender. Some have found hypermetropic errors to be more common in females [20-22]. The Andhra Pradesh Eye Diseases Study (APEDS), which is the largest study regarding ocular morbidity in the South Indian population, found hyperme- tropic errors to be more common in urban females in the 16-29 years age group [20] compared to urban males, and myopic errors in rural females of 7-15 years age group [23] compared to rural males. The study from Kashmir [11] found no significant difference between males and females overall. To the knowledge of the investigators, only two similar community-based studies of schoolchildren have been conducted till date in Bihar - in one study, screening for refractive errors in 252 children aged 11-16 years revealed prevalence of refractive errors in $17.5 \%$ of males and $19.4 \%$ of females [24]. Another study, on the contrary, observed that among 131 children aged 10-14 years, screening revealed refractive errors in about $25.8 \%$ of males and $17.7 \%$ of females [25]. These studies, however, did not analyse if particular refractive errors are more prevalent in a particular gender.

Reports from the WHO have stated that refractive errors are a growing problem among urban people in South-East Asia [4]. In Indian studies, myopia was prevalent amongst $4.1 \%$ rural [20] as compared to $7.4 \%$ amongst urban children [26]. Hypermetropia was found to be prevalent in $0.8 \%$ of rural [23] as compared to $7.7 \%$ urban children [26].

The APEDS [20] found that among rural persons aged 21-60 years, the more educated had more myopia and less hypermetropia compared to the less educated, while a study from Bangladesh [34] found the converse, that educational level is significantly associated with hypermetropia. These findings are not specific to young people.

Even with extensive literature review, the pattern of refractive errors that is prevalent among young people presenting to tertiary care institutions in Bihar state of India is yet unknown. We undertook the present epidemiological study with the objective to determine the clinico-demographic profile of young people presenting to our tertiary institution with refractive errors, as an initial step to enable hospital services to cater to them in a better manner, increasing their productivity for the development of the nation.

\section{MATERIAL AND METHODS}

A prospective observational study was conducted at the outpatient department (OPD) of the Upgraded Department of Ophthalmology of a medical college of Bihar, India, with its patients aged 10-24 years as the study population. Both objective 
and subjective methods of refraction were used to assess refractive error in OPD patients with subnormal visual acuity improving with pinhole, and those with asthenopic symptoms. Patients with bilateral organic defects such as strabismus, corneal opacity, the opacity of the lens, and choroid and retinal disorders were excluded. Eyes with unilateral organic defects were also excluded from consideration [7, 23].

The objective method of autorefraction was employed first, using the Topcon RM-8800 autorefractor (Topcon Inc., USA) without cycloplegia-mydriasis. This was followed by subjective verification of refractive prescription using a standard trial frame and lenses and Snellen's Chart for 6 metres distance. Subsequently, upon the clinical decision in patients with asthenopia, autorefraction was repeated with cycloplegia-mydriasis using Cyclopentolate $1 \%$ alternating with tropicamide $0.8 \%+$ phenylephrine 5\% eye drops [CTC technique (cyclopentolate-tropicamide-cyclopentolate)] followed by subjective verification.

Myopia was said to have been diagnosed in a particular eye when refractive correction prescribed amounted to $\geq 0.50 \mathrm{DSph}(-)$ without any cylindrical correction. Similarly, hypermetropia was diagnosed when refractive correction prescribed amounted to $\geq 0.50 \mathrm{DSph}(+)$ without any cylindrical correction. Myopic astigmatism was diagnosed when the power was $\geq 0.50 \mathrm{DCyl}(-)$ with zero or negative spherical correction. Similarly, hypermetropic astigmatism was diagnosed when the power was $\geq 0.50 \mathrm{DCyl}(+)$ with zero or positive spherical correction. Mixed astigmatism was diagnosed if the power contained both spherical and cylindrical corrections bearing opposite mathematical signs but with numerical values $\geq 0.50 \mathrm{D}$ despite transposition.

The Indian Council of Medical Research (ICMR) and the Institutional Ethics Committee approved the study protocol. Accordingly, informed consent was obtained from the patients over 18 years of age and from the accompanying guardians of patients under 18 years of age. Using a pre-structured performa over a two-month period, clinico-demographic information with respect to their age, gender, residential background and literacy was collected along with recording for each eye, the refractive error diagnosed subsequently.

Raw data was entered in Microsoft Excel Spreadsheet 2013 (Microsoft Corporation, USA). Statistical Analyses were performed using the software SPSS 16.0 for Windows (Statistical Package for the Social Sciences, SPSS Inc., USA). Bivariate com- parisons were made between the demographic variables and the types of refractive errors found. For qualitative analysis, the Chi-Square test was applied, taking $\mathrm{p}<0.05$ as significant.

\section{RESULTS}

During the study period, refractive correction was prescribed for a total of 1482 young people (2739 eyes). Among them, hypermetropic errors were more common [about 51\%; comprising of hypermetropia (about 32\%) and hypermetropic astigmatism (about 19\%)]. This closely exceeded myopic errors [about 49\%; myopic astigmatism (about 26\%) and myopia (about 22\%)]. The difference between the spherical and astigmatic errors was statistically significant $\left(\chi^{2}=2367.35\right.$, $\mathrm{df}=1, \mathrm{p}<0.001)$. Mixed astigmatism was the least common among all refractive errors $(0.43 \%)$ (Tab. 1).

More young people from the 20-24 years age group (710 patients; 1347 eyes, about 50\%) presented to the OPD compared to the 10-14 years (133 patients; 230 eyes, 8\%) and 15-19 years (639 patients; 1162 eyes, 42\%) age-groups. Myopic errors were more common in the 10-14 years age group $(76 \%)$, while hypermetropic errors were more common and approximately equal in the 15-19 years (53\%) and 20-24 years age group (54\%). This difference was statistically significant $\left(\chi^{2}=107.554, \mathrm{df}=4, \mathrm{p}<0.001\right)$. Mixed astigmatism remained low across all age-groups (Tab. 1, Fig. 1).

More males (81\%) presented to the OPD than females (19\%). Myopia was found to be the most prevalent refractive error in females (39\%) while in males, this was the case with hypermetropia $(37 \%$, Tab. 1, Fig. 2). The distribution of refractive errors among the genders was statistically significant $\left(\chi^{2}=115.701, \mathrm{df}=2, \mathrm{p}<0.001\right)$. Also, spherical errors were significantly more common in males, and astigmatism in females $\left(\chi^{2}=6.888, \mathrm{df}=1\right.$, $\mathrm{p}=0.009 ; \mathrm{OR}=1.29$ ).

More urban $(88 \%)$ than rural patients (12\%) visited the OPD. Among rural patients, myopia was more common (53\%), while among urban patients, this was the case with hypermetropia (35\%, Tab. 1 , Fig. 3). This difference was statistically significant $\left(\chi^{2}=104.873, \mathrm{df}=2, \mathrm{p}<0.001\right)$. Also, spherical errors were significantly more common in rural, and astigmatism in urban patients $\chi^{2}=14.172, \mathrm{df}=1$, $\mathrm{p}<0.001$; OR $=1.59$ ). 


\begin{tabular}{|c|c|c|c|c|c|c|c|c|}
\hline & \multirow{2}{*}{$\begin{array}{c}\text { Grand } \\
\text { Total } \\
(\%)\end{array}$} & \multicolumn{3}{|c|}{ Myopic errors } & \multicolumn{3}{|c|}{ Hypermetropic errors } & \multirow{2}{*}{$\begin{array}{c}\text { Mixed } \\
\text { astigmatism } \\
(\%)\end{array}$} \\
\hline & & $\begin{array}{l}\text { Total } \\
(\%)\end{array}$ & $\begin{array}{c}\text { Myopia } \\
(\%)\end{array}$ & $\begin{array}{c}\text { Myopic } \\
\text { astigmatism (\%) }\end{array}$ & $\begin{array}{l}\text { Total } \\
(\%)\end{array}$ & $\begin{array}{c}\text { Hypermetropia } \\
(\%)\end{array}$ & $\begin{array}{l}\text { Hypermetropic } \\
\text { astigmatism (\%) }\end{array}$ & \\
\hline $\begin{array}{l}\text { Number } \\
\text { of eyes }\end{array}$ & $\begin{array}{c}2739 \\
(100.0)\end{array}$ & $\begin{array}{c}1331 \\
(48.6)\end{array}$ & $\begin{array}{c}610 \\
(22.3)\end{array}$ & $\begin{array}{c}721 \\
(26.3)\end{array}$ & $\begin{array}{l}1396 \\
(51.0)\end{array}$ & $\begin{array}{c}879 \\
(32.1)\end{array}$ & $\begin{array}{c}517 \\
(18.9)\end{array}$ & $\begin{array}{c}12 \\
(0.4)\end{array}$ \\
\hline \multicolumn{9}{|l|}{ Age group } \\
\hline $10-14$ years & $\begin{array}{c}230 \\
(100.0)\end{array}$ & $\begin{array}{c}174 \\
(75.7)\end{array}$ & $\begin{array}{c}99 \\
(43.0)\end{array}$ & $\begin{array}{c}75 \\
(32.6)\end{array}$ & $\begin{array}{c}50 \\
(21.7)\end{array}$ & $\begin{array}{c}23 \\
(10.0)\end{array}$ & $\begin{array}{c}27 \\
(11.7)\end{array}$ & $\begin{array}{c}6 \\
(2.6)\end{array}$ \\
\hline $15-19$ years & $\begin{array}{c}1162 \\
(100.0)\end{array}$ & $\begin{array}{c}539 \\
(46.4)\end{array}$ & $\begin{array}{c}151 \\
(13.0)\end{array}$ & $\begin{array}{c}388 \\
(33.4)\end{array}$ & $\begin{array}{c}619 \\
(53.3)\end{array}$ & $\begin{array}{c}442 \\
(38.0)\end{array}$ & $\begin{array}{c}177 \\
(15.2)\end{array}$ & $\begin{array}{c}4 \\
(0.3)\end{array}$ \\
\hline $20-24$ years & $\begin{array}{c}1347 \\
(100.0)\end{array}$ & $\begin{array}{c}618 \\
(45.9)\end{array}$ & $\begin{array}{c}360 \\
(26.7)\end{array}$ & $\begin{array}{c}258 \\
(19.2)\end{array}$ & $\begin{array}{c}727 \\
(54.0)\end{array}$ & $\begin{array}{c}414 \\
(30.7)\end{array}$ & $\begin{array}{c}313 \\
(23.2)\end{array}$ & $\begin{array}{c}2 \\
(0.1)\end{array}$ \\
\hline \multicolumn{9}{|l|}{ Gender } \\
\hline Male & $\begin{array}{c}2213 \\
(100.0)\end{array}$ & $\begin{array}{c}968 \\
(43.7)\end{array}$ & $\begin{array}{c}403 \\
(18.2)\end{array}$ & $\begin{array}{c}565 \\
(25.5)\end{array}$ & $\begin{array}{l}1238 \\
(55.9)\end{array}$ & $\begin{array}{c}827 \\
(37.4)\end{array}$ & $\begin{array}{c}411 \\
(18.6)\end{array}$ & $\begin{array}{c}7 \\
(0.3)\end{array}$ \\
\hline Female & $\begin{array}{c}526 \\
(100.0)\end{array}$ & $\begin{array}{c}363 \\
(69.0)\end{array}$ & $\begin{array}{c}207 \\
(39.4)\end{array}$ & $\begin{array}{c}156 \\
(29.7)\end{array}$ & $\begin{array}{c}158 \\
(30.0)\end{array}$ & $\begin{array}{c}52 \\
(9.9)\end{array}$ & $\begin{array}{c}106 \\
(20.2)\end{array}$ & $\begin{array}{c}5 \\
(1.0)\end{array}$ \\
\hline \multicolumn{9}{|l|}{ Residence } \\
\hline Rural & $\begin{array}{c}326 \\
(100.0)\end{array}$ & $\begin{array}{c}245 \\
(75.2)\end{array}$ & $\begin{array}{c}173 \\
(53.1)\end{array}$ & $\begin{array}{c}72 \\
(22.1)\end{array}$ & $\begin{array}{c}81 \\
(24.8)\end{array}$ & $\begin{array}{c}36 \\
(11.0)\end{array}$ & $\begin{array}{c}45 \\
(13.8)\end{array}$ & $\begin{array}{c}0 \\
(0.0)\end{array}$ \\
\hline Urban & $\begin{array}{c}2413 \\
(100.0)\end{array}$ & $\begin{array}{l}1086 \\
(45.0)\end{array}$ & $\begin{array}{c}437 \\
(18.1)\end{array}$ & $\begin{array}{c}649 \\
(26.9)\end{array}$ & $\begin{array}{r}1315 \\
(54.5)\end{array}$ & $\begin{array}{c}843 \\
(34.9)\end{array}$ & $\begin{array}{c}472 \\
(19.6)\end{array}$ & $\begin{array}{c}12 \\
(0.5)\end{array}$ \\
\hline \multicolumn{9}{|l|}{ Education } \\
\hline Literate & $\begin{array}{c}2335 \\
(100.0)\end{array}$ & $\begin{array}{l}1098 \\
(47)\end{array}$ & $\begin{array}{c}559 \\
(23.9)\end{array}$ & $\begin{array}{c}539 \\
(23.1)\end{array}$ & $\begin{array}{r}1225 \\
(52.5)\end{array}$ & $\begin{array}{c}726 \\
(31.1)\end{array}$ & $\begin{array}{c}499 \\
(21.4)\end{array}$ & $\begin{array}{c}12 \\
(0.5)\end{array}$ \\
\hline Illiterate & $\begin{array}{c}404 \\
(100.0)\end{array}$ & $\begin{array}{c}233 \\
(57.7)\end{array}$ & $\begin{array}{c}51 \\
(12.6)\end{array}$ & $\begin{array}{c}182 \\
(45.6)\end{array}$ & $\begin{array}{c}171 \\
(42.3)\end{array}$ & $\begin{array}{c}153 \\
(37.1)\end{array}$ & $\begin{array}{c}18 \\
(4.5)\end{array}$ & $\begin{array}{c}0 \\
(0.0)\end{array}$ \\
\hline
\end{tabular}

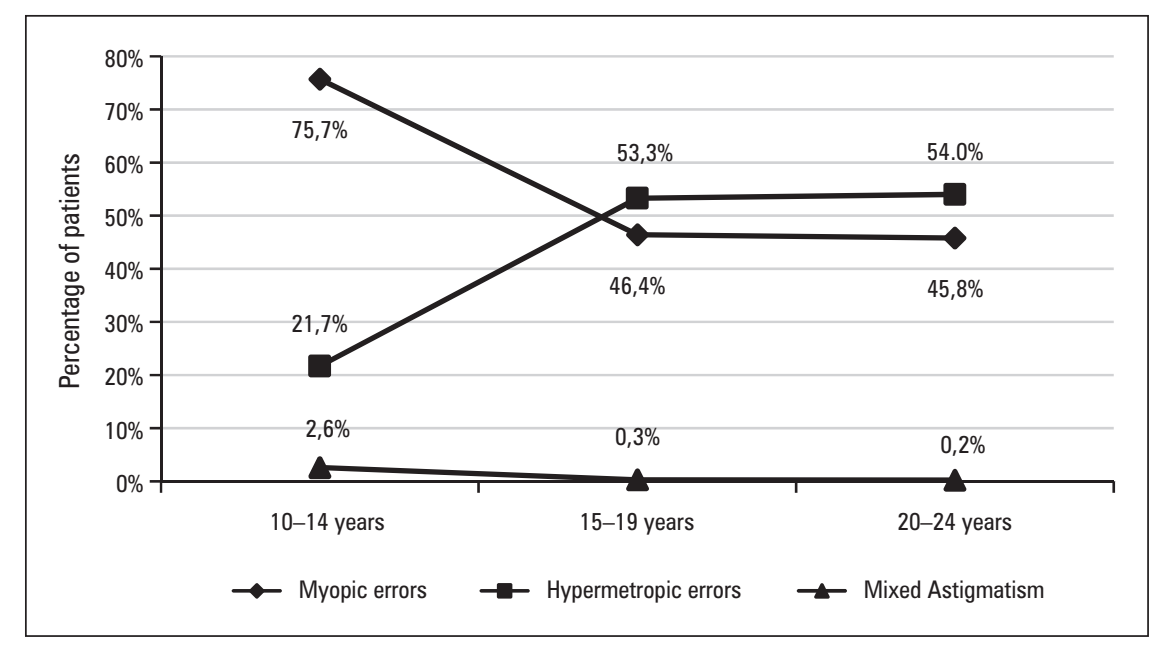

FIGURE 1. Comparison of refractive status with age-group $(n=2739)$

More literate $(85 \%)$ than illiterate patients $(15 \%)$ visited the OPD. Among literate patients, hypermetropia was more common $(31 \%)$, while among illiterate patients, this was the case with myopic astigmatism (45\%, Tab. 1, Fig. 4). This difference was statistically significant $\left(\chi^{2}=17.057\right.$, 


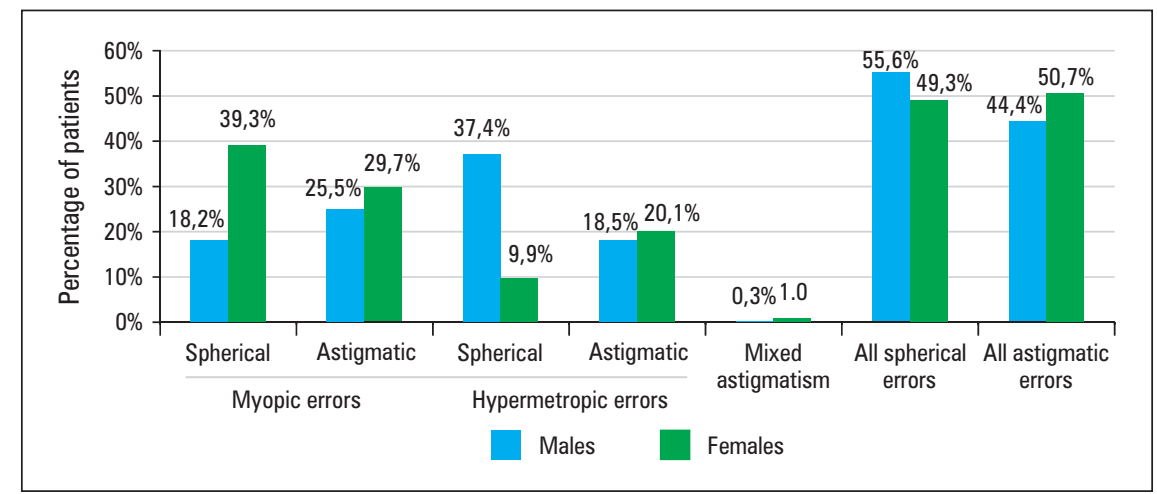

FIGURE 2. Comparison of refractive status with gender $(n=2739)$

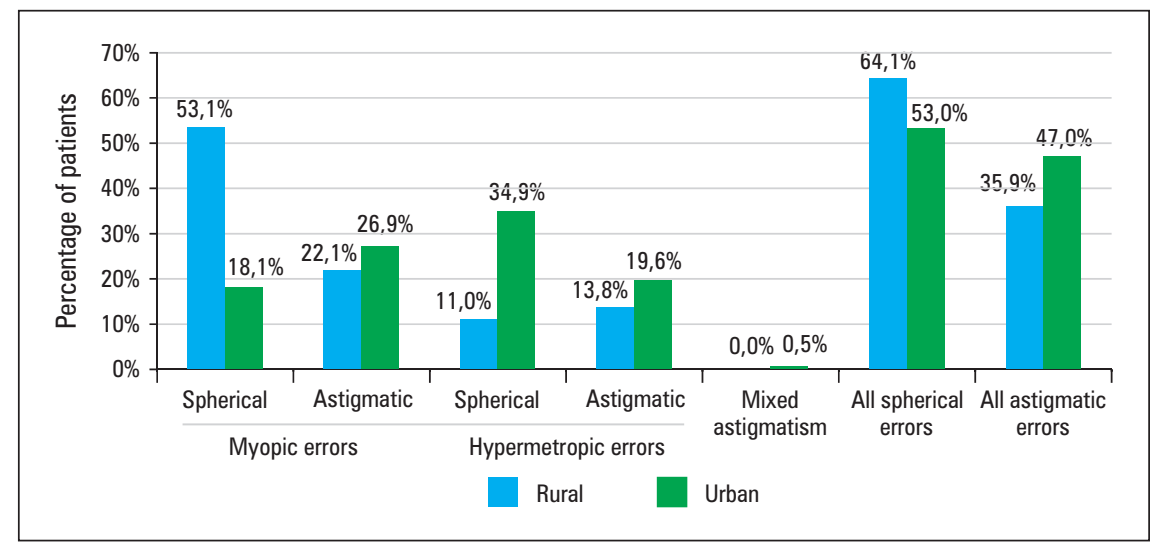

FIGURE 3. Comparison of refractive status with residential background $(n=2739$ )

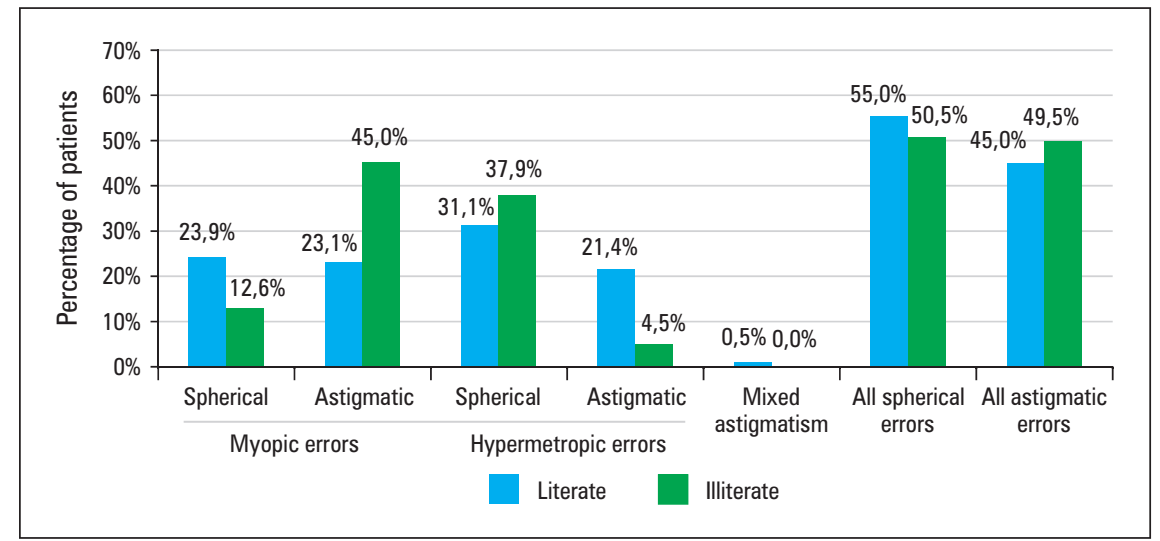

FIGURE 4. Comparison of refractive status with education $(n=2739)$

$\mathrm{df}=2, \mathrm{p}<0.001)$. Spherical errors were more common in the literate than astigmatism in the illiterate, but this was not significant $\chi^{2}=2.858, \mathrm{df}=1$, $\mathrm{p}=0.091 ; \mathrm{OR}=1.20)$.

\section{DISCUSSION}

This study of 2739 eyes of 1482 young persons aged 10 to 24 years, an age-range that consists of extremely important formative and early produc- 
tive years of citizens, was conducted to find out the distribution of refractive errors amongst them. It was conducted in a high-volume tertiary centre that meets the felt need of this section of the population, mostly students.

A large number of previous studies [9-27] have attempted to fill the gaps in knowledge regarding the distribution of refractive errors. In the present study, the frequencies of refractive errors, in descending order, were found as follows: hypermetropia (32\%), myopic astigmatism $(26 \%)$, myopia (22\%), hypermetropic astigmatism (19\%), and mixed astigmatism (0.4\%; Fig. 1, Tab. 1). Overall, hypermetropic errors were more common (51\%) than myopic errors (49\%), but the difference was marginal. This presents an opposite picture when compared to various other studies which concluded that myopic errors (inclusive of myopia [11-18] and myopic astigmatism [19]) are the most common refractive errors in the population. The hospital data from the present study probably represent a compound picture wherein hypermetropia is more frequent in OPD patients because it is the refractive error causing the most asthenopic symptoms and thereby the need to visit the OPD; it is followed by myopic astigmatism and myopia that are the most common refractive errors in the population. This emphasizes that addressing the problem of hypermetropia may be more important in a hospital setting than previously thought.

In the present study, the young people who presented to the OPD belonged more to the $20-24(50 \%)$ and $15-19$ years age group (42\%) compared to the 10-14 (8\%) age group. This agrees with the studies in Kashmir [11], West Bengal [12] and Odisha [15], which found that refractive errors in adolescents peaked in the upper age-groups. It may be explained by the fact that asthenopia is increasingly manifested in students receiving higher education with the need for long periods of study. The present hospital-based study has found myopic errors to be more common in the 10-14 years age group (76\%), and hypermetropic errors to be more common (and approximately equal in frequency) in the $15-19$ years $(53 \%)$ and $20-24$ years age groups $(54 \%$, Tab. 1, Fig. 1). An increase in the presentation in the OPD of hypermetropic errors with age may be attributed to hypermetropia causing more asthenopic symptoms as discussed above.

As previously stated, available literature presents a conflicting picture regarding the gender distribution of refractive errors in India in general [9-18] and Bihar in particular [24, 25]. In the present study, about four times as many males presented to the OPD with refractive error as females, and myopic errors in general and myopia, in particular, were the most prevalent refractive error in females (39\%, Tab. 1, Fig. 2). The difference could be probably because cultural constraints enable more males to step out of their homes for education than females. In addition, because myopia causes less asthenopia compared to hypermetropia, and, as above, although myopic errors are more common in females, a large proportion of females in the community would rather prefer not to wear glasses and not arrive for OPD consultation at all. However, the argument provided by the APEDS [20], that females have smaller eyes applies in India, does not seem to stand true. In addition, spherical errors were significantly more common in males, and astigmatic errors in females $(\mathrm{p}=0.009 ; \mathrm{OR}=1.29)$. No comparable studies could be found in this regard.

Far more urban (88\%) than rural young people $(12 \%)$ visited the OPD. This is because the hospital is situated in an urban area, but may reflect that refractive errors are a growing problem in urban settings as identified by the WHO [4]. The reasons of reporting to a tertiary care hospital have been enumerated in a previous study [8]. Among rural patients, myopia was more common (53\%), while among urban patients, this was the case with hypermetropia (35\%, Tab. 1, Fig. 3). This difference was statistically significant $(p<0.001)$. This disagrees with the population-based Indian studies comparing similar age-groups $[20,26]$, wherein both myopia $(7.4 \%$ vs. $4.1 \%)$ and hypermetropia $(7.7 \%$ vs. $0.8 \%)$ were more common amongst urban children. In addition, spherical errors were significantly more common in rural, and astigmatisms in urban patients $(\mathrm{p}<0.001, \mathrm{OR}=1.59)$. No comparable studies could be found in this regard.

More literate $(85 \%)$ than illiterate patients (15\%) visited the OPD. This is because the medical college is flanked with a number of educational institutions in the vicinity. Among literate patients, hypermetropia was most common $(31 \%$, Tab. 1, Fig. 4) which was similar to a study from Bangladesh [27] but contrary to APEDS [20]. These studies found myopia more prevalent in the educated, whereas in the present study, myopic astigmatism was found to be more common in rural patients $(45 \%)$. This was a statistically 
significant difference $(\mathrm{p}<0.001)$, probably arising out of the particular age-range considered in the present study, as well as the protocol of performing cycloplegia in all patients who reported asthenopic symptoms. Spherical errors were more common in the literate than astigmatisms in the illiterate, but this was not significant $(\mathrm{p}=0.091$; $\mathrm{OR}=1.20)$

The present study provides a broad picture of refractive errors and the clinico-demographic profile of patients who present to the ophthalmology OPD. Further multi-centric studies could be done to compare medical college hospitals in rural areas with urban ones and to compare tertiary hospitals of different states at different stages of development, that would have a bearing on the prevalent conditions of care in rural areas in order to enact a uniform standard of basic minimum care for the country.

\section{CONCLUSION}

This study yielded several insights into the clinico-demographic profile of young people presenting with refractive errors to the Ophthalmology OPD of the medical college hospital. It achieved its objectives in providing a broad picture of an area of research that has stayed unattended in the state of Bihar, India.

It is concluded that in the outpatient setting of the tertiary hospital, there is a predominance of symptomatic myopic errors in the age group of 10-14 years, which changes to hypermetropic in the age group 15-19 and 20-24 years. There is a predominance of myopia in females and rural young people, of myopic astigmatism in the illiterate but hypermetropia in males, in urban young people and the literate. Addressing the problem of hypermetropia may be more important in a hospital setting than previously thought.

\section{Conflict of interests}

The authors report no competing interests.

\section{Funding source}

Indian Council of Medical Research (ICMR) vide STS award, reference number 2015-04003.

\section{REFERENCES}

1. Park K. Textbook of Preventive and Social Medicine, 22nd Ed. M/S Banarsidas, Bhanot 2013: 548.

2. Bourne R, Flaxman S, Braithwaite T, et al. Magnitude, temporal trends, and projections of the global prevalence of blindness and distance and near vision impairment: a systematic review and meta-analysis. Lancet Global Health. 2017; 5(9): e888-e897, doi: 10.1016/s2214109x(17)30293-0.

3. World Health Organisation, Action Plan 2006-2011, VISION 2020 Global Initiative for the Elimination of Avoidable Blindness. https://www. iapb.org/wp-content/uploads/VISION-2020-Action-Plan-2006-2011. pdf.

4. Resnikoff S, Pascolini D, Mariotti SP, et al. Global magnitude of visual impairment caused by uncorrected refractive errors in 2004. Bull World Health Organ. 2008; 86(1): 63-70, doi: 10.2471/blt.07.041210, indexed in Pubmed: 18235892.

5. National blindness and visual impairment survey India 2015-2019: A summary report, Ministry of Health and Family Welfare, Government of India: 2.

6. Honavar SG. The burden of uncorrected refractive error. Indian $\mathrm{J}$ Ophthalmol. 2019; 67(5): 577-578, doi: 10.4103/ijo.IJO_762_19, indexed in Pubmed: 31007210.

7. Sinha S, Sinha RK, Nishant P. Prevalence of spectacle use and amblyopia among young people presenting to a tertiary care institution of Bihar. Trop J Ophthal Otolaryngol. 2019; 4(2): 151-156, doi: 10.17511/ j000.2019.i02.14.

8. Nishant $P$, Sinha $S$, Sinha RK. Refraction-seeking behaviour among young people presenting to a medical college hospital of Bihar. Ind $\mathrm{J}$ Clin Exp Ophthalmol. 2018; 4(2): 254-257, doi: 10.18231/23951451.2018.0056.

9. Sudhan A, Pandey KP, Khare M, et al. Vision Centre' as a strategy to provide eye care services to underserved populations: Results from Satna district of Madhya Pradesh, India. Community Eye Health J Indian Supplement. 2008; 21(68): 117-118.

10. Bhardwaj M, Singh L, Gupta A, et al. Pattern of refractive errors among the patients presenting to eye department of district hospital of Uttarakhand. Ind J Clin Exp Ophthalmol. 2016; 2(3): 248, doi: 10.5958/23951451.2016.00053.6.

11. Rohul J, Maqbool A, Hussain S, et al. Prevalence of Refractive Errors in Adolescents in Out-patient Attendees of the Preventive Ophthalmology Clinic of Community Medicine, SKIMS, Kashmir, India. J Health Allied Sci NU. 2013; 03(01): 17-20, doi: 10.1055/s0040-1703627.

12. Saha M, Ranjan A, Islam MN, et al. Prevalence of Refractive Errors among the School going Children at a Tertiary Center of West Bengal. Int J Sci Stud. 2017; 5: 179-182.

13. Natung $T$, Taye $T$, Lyngdoh $L A$, et al. Refractive errors among patients attending the ophthalmology department of a medical college in North-East India. J Family Med Prim Care. 2017; 6(3): 543-548, doi: 10.4103/2249-4863.222023, indexed in Pubmed: 29417005.

14. Hazarika $H$, Bhuyan $D$, Hazarika $S$, et al. Refractive errors in age group seven to fifteen years: North-east India scenario. Int J Community Med Public Health. 2017; 4(6): 1928, doi: 10.18203/2394-6040.ijcmph20172151.

15. Rao GN, Sabnam S, Pal S, et al. Prevalence of ocular morbidity among children aged 17 years or younger in the eastern India. Clin Ophthalmol. 2018; 12: 1645-1652, doi: 10.2147/0PTH.S171822, indexed in Pubmed: 30233126.

16. Singh HV, Kumar D. Refractive error scenario in paediatric age group (7-15 years) in Assam: A hospital based study. IP Int J Ocul Oncol Oculoplasty. 2019; 4(4): 148-150, doi: 10.18231/25815016.2018.0038.

17. Mittal S, Maitreya A, Dhasmana R. Clinical profile of refractive errors in children in a tertiary care hospital of Northern India. Int J Community Med Public Health . 2016: 1189-1194, doi: 10.18203/2394-6040. ijcmph20161382.

18. Matta S, Matta P, Gupta V, et al. Refractive Errors among Adolescents attending Ophthalmology OPD. Ind J Comm Med. 2006; 31: 114-115.

19. Rizyal A, Ghising R, Shrestha RK, et al. Pattern of refractive errors among patients at a tertiary hospital in Kathmandu. Nepal Med Coll $\mathrm{J}$ . 2011; 13(3): 172-174, indexed in Pubmed: 22808808.

20. Dandona R, Dandona L, Naduvilath TJ, et al. Refractive Errors in an Urban Population in Southern India: The Andhra Pradesh Eye Disease Study. Invest Ophthalmol Vis Sci. 1999; 40: 2810-2818, indexed in Pubmed: 10549640. 
21. Raju P, Ramesh SVe, Arvind H, et al. Prevalence of refractive errors in a rural South Indian population. Invest Ophthalmol Vis Sci. 2004; 45(12): 4268-4272, doi: 10.1167/iovs.04-0221, indexed in Pubmed: 15557431.

22. Kalikivayi V, Naduvilath TJ, Bansal AK, et al. Visual impairment in school children in Southern India. Indian J Ophthalmol. 1997; 45(2): 129-134, indexed in Pubmed: 9475034.

23. Dandona $R$, Dandona $L$, Srinivas $M$, et al. Refractive error in children in a rural population in India. Invest Ophthalmol Vis Sci. 2002; 43(3): 615-622, indexed in Pubmed: 11867575.

24. Bharati D. A cross-sectional study on pattern of ocular morbidity and the prevalence of refractive errors among school children of 11 to 16 years in the rural area of Maner, Patna Bihar, India. J Med Sci Clin Res. 2019; 7(2), doi: 10.18535/jmscr/v7i2.46.

25. Sinha RK. Ocular Morbidity Pattern in Schoolchildren in Muzaffarpur, Bihar. J Ophthalmol. 2006; 31: 66-67.

26. Murthy GV, Gupta SK, Ellwein LB, et al. Refractive error in children in an urban population in New Delhi. Invest Ophthalmol Vis Sci. 2002; 43(3): 623-631, indexed in Pubmed: 11867576.

27. Bourne RRA, Dineen BP, Huq DM, et al. Correction of refractive error in the adult population of Bangladesh: meeting the unmet need. Invest Ophthalmol Vis Sci. 2004; 45(2): 410-417, doi: 10.1167/iovs.03-0129, indexed in Pubmed: 14744879. 